\title{
Determination of particulate matter vertical columns using satellite observations
}

\author{
A. A. Kokhanovsky ${ }^{1}$, A. S. Prikhach ${ }^{2}$, I. L. Katsev ${ }^{2}$, and E. P. Zege ${ }^{2}$ \\ ${ }^{1}$ Institute of Environmental Physics, O. Hahn Allee 1, 28334 Bremen, Germany \\ ${ }^{2}$ Institute of Physics, National Academy of Sciences of Belarus, Nezavisimosti Prospekt 68, 220068, Minsk, Belarus
}

Received: 23 February 2009 - Published in Atmos. Meas. Tech. Discuss.: 9 April 2009

Revised: 5 June 2009 - Accepted: 15 June 2009 - Published: 13 July 2009

\begin{abstract}
A new technique to retrieve the particulate matter vertical columns from spaceborne observations is described. The method is based on the measurements of the spectral aerosol optical thickness (AOT). The spectral slope of the derived aerosol optical thickness is used to infer the size of particles, which is needed (along with the absolute value of AOT) to determine corresponding vertical columns. The technique is applied to the case of a cloudless atmosphere over Germany and results are compared with ground-based observations. Several assumptions are made in the retrieval process such as the prescribed phase function, single scattering albedo, the refractive index of aerosol, and the half-width of the size distribution.
\end{abstract}

\section{Introduction}

Atmospheric gases (e.g., $\mathrm{O}_{3}, \mathrm{SO}_{2}, \mathrm{NO}_{2}$ ) and particles suspended in atmosphere are known to contribute to the increased mortality in areas with high concentrations of corresponding pollutants (Altshuller, 1972; Pope et al., 2002). Therefore, there is an urgent task to monitor and reduce levels of pollution. The corresponding ground-based observation systems are in place in a number of national environmental agencies. Most of these systems do not include satellite observations at the moment. Browse imagery of cloud fields is known to everybody due to weather forecasts broadcasted on TV. Similar forecasts must be developed for the gaseous and particulate matter pollution monitoring based on spaceborne observations from a geostationary orbit. Snapshots derived using polar orbiting instruments are of importance as well.

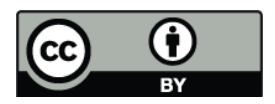

Correspondence to: A. A. Kokhanovsky (alexk@iup.physik.uni-bremen.de)
The top-of-atmosphere (TOA) reflectance measured by an optical instrument on a satellite platform is determined not only by the underlying surface reflectance of solar light (e.g., snow, ice, sand, vegetation) but also by vertical distributions of microphysical characteristics of particles and gases suspended in atmosphere. Therefore, there is a possibility to derive vertical columns of gases and also suspended particles from passive spectral top-of-atmosphere solar light reflectance measurements. This subject is actively explored at the moment in a number of national and international agencies and research organizations (Burrows, 1999; Borell et al., 2004; Al-Saadi et al., 2005). The task of this paper is to introduce a novel technique for the determination of particulate matter vertical concentration from space. The size of particles needed in the calculation of the aerosol mass is derived from the retrieved spectral aerosol optical thickness (see, e.g., Griggs, 1975, 1979). This makes it different our technique from other methods, where the size of particles was assumed in the retrieval process (see, e.g., Fraser et al., 1976, 1984; Kaufman and Fraser, 1990; Gasso and Hegg, 1997, 2003).

The paper is structured as follows. In the next section we present the methodology of particulate matter vertical columns (PMVC) retrievals from space developed by us. The Sect. 3 is aimed at the applications and the validation of the developed technique using ground-based measurements. Outlook and conclusions are discussed in the final section of the paper.

\section{Methodology}

The retrieval of aerosol mass concentration using spaceborne observations has been performed by several groups (Fraser, 1976; Fraser et al., 1984; Kaufman and Fraser, 1990; Gasso and Hegg, 1997, 2003). They are based on the fact

Published by Copernicus Publications on behalf of the European Geosciences Union. 
that the aerosol number concentration per unit area $n=N L$ (for the beginning let us consider a homogeneous layer, $N$ is the number concentration of particles $\left(\mathrm{cm}^{-3}\right), L$ is the geometrical thickness of this layer) can be related to the aerosol optical thickness (AOT) $\tau$ routinely measured by satellites both over land and ocean (see, e.g., Remer et al., 2005; Kokhanovsky and de Leeuw, 2009). Namely it follows:

$n=A \tau$,

where the constant $A$ depends on the particle size distribution, the chemical composition and the shape of particles. It is often assumed for the simplification of the particulate matter (PM) retrievals that the tropospheric aerosol is mostly contained in a lower atmospheric boundary layer (with the thickness $L$ of $1 \mathrm{~km}$ or so) and well mixed there. Then it follows for a homogeneous aerosol layer:

$A=\frac{1}{C_{\mathrm{ext}}}$,

where $C_{\text {ext }}$ is the average extinction cross section of particles in a mixing layer. The value of $L$ can be measured, e.g., with a lidar. Then the concentration $N$ can be also estimated.

The aerosol mass concentration $m$ per unit area $\left(\mathrm{g} / \mathrm{cm}^{2}\right)$ can be found from the following equation:

$m=n V \rho$,

where $V$ is the average volume of particles and $\rho$ is the average density of aerosol particles assumed to be equal $1 \mathrm{~g} / \mathrm{cm}^{3}$ in this work. Therefore, the final equation reads (see Eqs. 1, 2):

$m=\frac{V \rho \tau}{C_{\mathrm{ext}}}$,

or, introducing the effective optical size of particles (OSP)

$a=V / C_{\mathrm{ext}}$,

one derives:

$m=a \rho \tau$.

It follows in the case of a homogeneous layer for the aerosol mass concentration $\left(\mathrm{g} / \mathrm{cm}^{3}\right): M=m / L$. Therefore, the mass concentration $M$ correlates with the product $a \rho \tau L^{-1}$ rather than with $\tau$ itself. This in part explains the differences between seasonal patterns of AOT as compared to the ground-measured PM seasonal variations described by Xia et al. (2006). Other reason for such differences could be the aerosol vertical distribution (e.g., decoupling of aerosol layers with a heavy load of particles from the atmospheric boundary layer). Strong correlations between PM and $\tau$ as described, e.g., by Al-Saadi et al. (2005) should be taken with caution (at least as far as the universal nature of these correlations is of concern).

The OSP (or scaling constant) $a$ should be studied depending on air masses, season, and locations. Also theoretical calculations of this parameter could be performed. For instance, it follows for large (the size is much larger than the wavelength $\lambda$ ) convex randomly oriented particles (van de Hulst, 1981): $C_{\text {ext }}=S / 2$, where $S$ is the average surface area of particles. This result does not depend on the shape and also on the chemical composition of particles providing that the size of particles is much larger than the wavelength and the refractive index is not close to unity. These conditions hold for the desert dust outbreaks. Then it follows:

$a=\frac{2 a_{e f}}{3}$,

where $a_{e f}=3 V / S$ is the effective radius (ER) of particles. Estimations of ER enable the determination of PMVC for dust outbreaks from the retrieved AOT (see Eq. 6). This is of importance, e.g., for calculations of particulate mass fluxes from deserts to oceans (Gasso and Hegg, 2003; Desboeufs and Cautenet, 2005).

The size of atmospheric particles in most of cases is smaller than the wavelength of the visible light. The typical effective radii are of about $100 \mathrm{~nm}$. Therefore, the approach for the calculation of the OSP $a$ for large particles given above can not be followed in most of cases. The retrieval of PMVC from space is possible, only if the correspondent model for the derivation of OSP is established. We propose the following route to estimate PMVC from satellite measurements:

- The aerosol optical thickness at several wavelengths $\lambda$ is determined from satellite measurements.

- The Angstrom coefficient $\alpha$ is determined as the slope of $\ln \tau(\lambda)$.

- The following analytical relationship between $a_{e f}$ and $\alpha$ is used: $a_{e f}=10^{p}(\mu \mathrm{m})$, where $p=\sum_{n=0}^{4} A_{n} \alpha^{n}$, $A_{0}=-0.07075, A_{1}=-1.03109, A_{2}=0.72806, A_{3}=$ $-0.41111, A_{4}=0.08106$. The constants $A_{j}$ were derived using the calculation of extinction coefficients with the Mie theory at the refractive index $1.45+0.005 \mathrm{i}$ and $\lambda=412$ and $670 \mathrm{~nm}$. The lognormal size distribution with the standard deviation equal to the average size of particles is used (the lognormal size distribution with the width parameter $\sigma=0.8326$, Kokhanovsky et al., 2006).

- The value of $C_{\text {ext }}$ is found from the parameterization of Mie calculations for the same size distribution as above using the derived value of $a_{e f}$ and assuming the complex refractive index of particles $1.45+0.005 \mathrm{i}$. In particular, the following relationship is used (Kokhanovsky et al., 2006): 


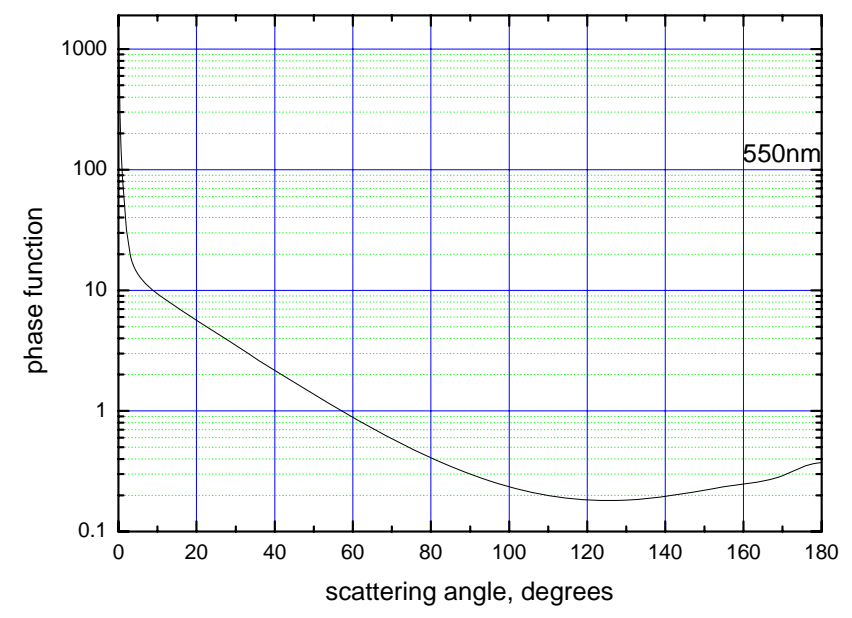

Fig. 1. The phase function used in retrievals.

$$
\begin{aligned}
& C_{\text {ext }}=\pi a_{e f}^{2} \exp \left(-3 \sigma^{2}\right) Q_{\text {ext }}, \\
& \lg \left(Q_{\text {ext }}\right)=\sum_{n=0}^{4} B_{n} \lg ^{n}\left(k a_{e f}\right),
\end{aligned}
$$

where $\sigma=0.8326, k=2 \pi / \lambda, \quad B_{0}=-0.367, \quad B_{1}=1.76$, $B_{2}=-1.024, B_{3}=-0.095, B_{4}=0.143$.

- The PMVC is found from Eq. (4), where the average volume $V$ is calculated from the derived $a_{e f}$ assuming the single mode lognormal distribution with the half-width equal to the average radius as proposed by Kokhanovsky et al. (2006). Namely, it follows: $V \approx \pi a_{e f}^{3} / 6$ at $\sigma=0.8326$. The value of $L$ can be found from lidar measurements or European Centre for Medium-Range Weather Forecasting (ECMWF) analysis. If the value of $L$ is known, then $\mathrm{PM}_{10}=\mathrm{PMVC} / L$ can be also determined.

As seen the proposed technique has advantages over the methods relying on a priori assumed values of OSP. The drawbacks of the model are the assumption of the fixed single mode particle size distribution and the refractive index of particles. They can be overcome in future, if the multi-angle space Stokes polarimeters will be launched (Mishchenko et al., 2005). This will bring a wealth of necessary information, which is not available in the spectral top-of-atmosphere measurements used in this paper and would allow to avoid some assumptions used in the technique described above. Therefore, several assumptions have been made to retrieve PMVC in this paper.

Now let us use the proposed technique to estimate PMVC from satellite data.

The algorithm for the determination of the aerosol optical thickness over land applied in this study (Katsev et al., 2009)

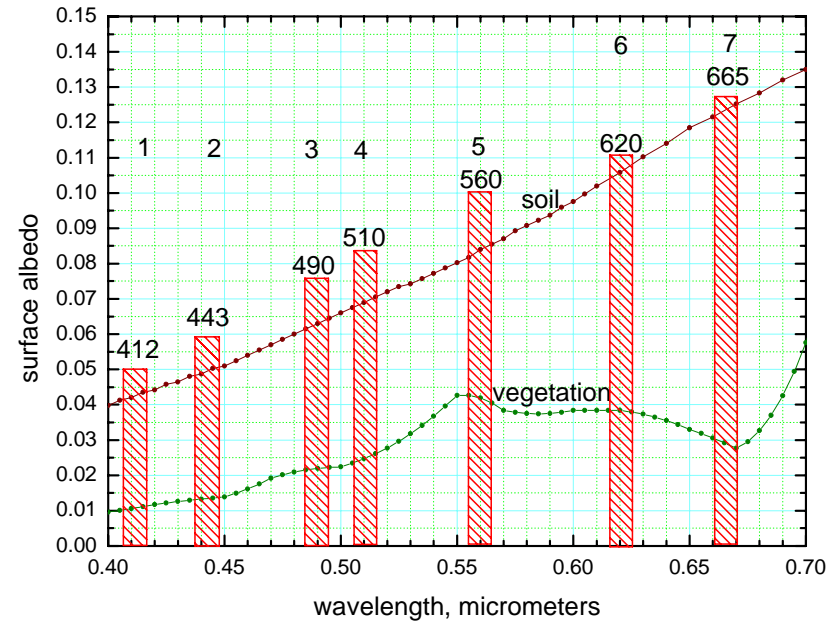

Fig. 2. The soil and vegetation spectral spherical albedos in the visible. MERIS channels 1-7 (in nm) are also shown. Spectra were obtained using airborne measurements (von Hoyningen-Huene et al., 2003).

will be reviewed in the next section. The PM retrieval technique as given above can be used in conjunction with any existing aerosol retrieval algorithm for the determination of $\tau(\lambda)$ over land or ocean. The correct determination of $\alpha$ is crucial for the performance of the algorithm.

\section{Retrievals and their validation}

\subsection{Aerosol optical thickness}

The spectral optical thickness and Angstrom parameter has been derived using the Aerosol Retrieval Technique (ART) developed by Katsev et al. (2009). The ART does not use the LUT technique but instead of it deploys our earlier developed extremely fast code RAY (see the code description in Katsev et al., 2009) for the vector radiative transfer computations. Retrievals in this paper are performed using standard continental aerosol model (WMO, 1986) (see Fig. 1). According to this model, the single scattering albedo is equal to 0.9 at the wavelength $\lambda=550 \mathrm{~nm}$. Over land, two a priori ground reflectance spectra are assumed (for the bare soil, $r_{s}(\lambda)$ and for the vegetated surface, $r_{v}(\lambda)$; see Fig. 2 ) in our retrieval procedure. The corresponding spectra were derived using measurements from a low altitude aircraft (von HoyningenHuene et al., 2003, 2006).

It is taken that a linear combination of these basic spectra with mixture parameter $c$ describes the ground reflectance spectra:

$r(\lambda)=c r_{v}(\lambda)+(1-c) r_{s}(\lambda)$

The parameters $\tau_{*} \equiv \tau(412 \mathrm{~nm}), \alpha$ and $c$ do not depend on the wavelength by definition. They are derived from the 


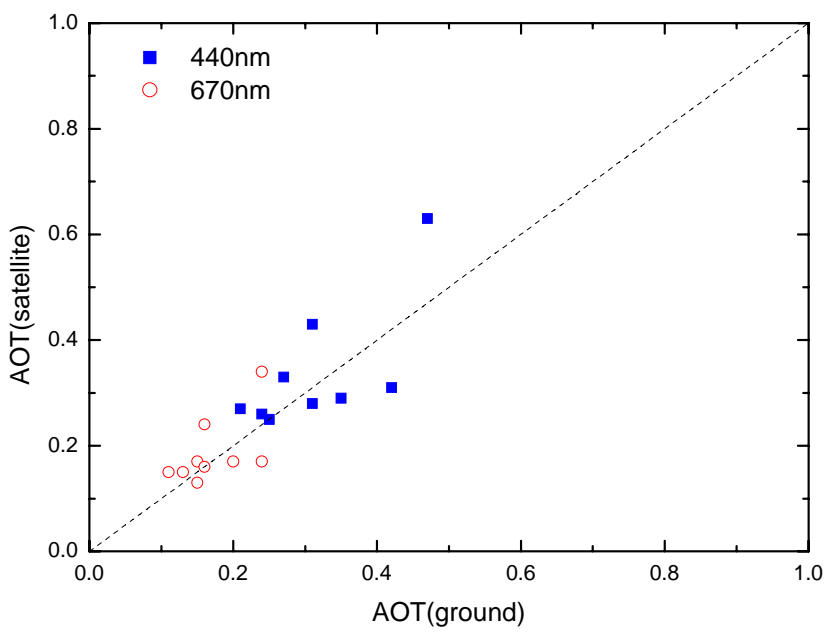

Fig. 3. The aerosol optical thickness correlation plot at the AERONET wavelengths $440 \mathrm{~nm}$ and $670 \mathrm{~nm}$.

measured spectral TOA reflectance with use of the least square technique by the iteration process.

We have selected the MEdium Resolution Imaging Spectrometer (MERIS) on board ENVIronmental SATellite (ENVISAT) data over Germany for 13 October 2005 for the validation of our technique. Clouds were almost absent at that day over most of Germany (Kokhanovsky et al., 2008). Full resolution MERIS scenes have the spatial resolution $260 \mathrm{~m}$ across track and $290 \mathrm{~m}$ along track. The reduced resolution mode used in this work has a spatial resolution $1040 \mathrm{~m}$ across track and $1160 \mathrm{~m}$ along track. Full resolution full scene has $2241 \times 2241$ pixels and covers $582 \mathrm{~km}$ (swath) by $650 \mathrm{~km}$ (azimuth). Reduced resolution scenes have $1121 \times 1121$ pixels and cover $1165 \mathrm{~km}$ (swath) by $1300 \mathrm{~km}$ (azimuth). MERIS performes measurements at the wavelengths $412.5 \mathrm{~nm}, 442.5 \mathrm{~nm}, 490 \mathrm{~nm}$, $510 \mathrm{~nm}, 560 \mathrm{~nm}, 620 \mathrm{~nm}, 665 \mathrm{~nm}, 681.3 \mathrm{~nm}, 708.8 \mathrm{~nm}$, $753.8 \mathrm{~nm}, 760.6 \mathrm{~nm}, 778.8 \mathrm{~nm}, 865 \mathrm{~nm}, 885 \mathrm{~nm}, 900 \mathrm{~nm}$. The channels at 670 and $865 \mathrm{~nm}$ have been used for the determination of Normalized Difference Vegetation Index (NDVI $=\left(\mathrm{R}\left(\lambda_{2}\right)-\mathrm{R}\left(\lambda_{1}\right)\right) /\left(\mathrm{R}\left(\lambda_{2}\right)+\mathrm{R}\left(\lambda_{1}\right)\right), \lambda_{1}=670 \mathrm{~nm}$, $\left.\lambda_{2}=865 \mathrm{~nm}\right)$ from the spectral reflectance $R(\lambda)$ measurements. NDVI is used as an initial guess value for $c$. All used channels have the bandwidth of $10 \mathrm{~nm}$ (except the channel at $865 \mathrm{~nm}$, which has the bandwidth of $20 \mathrm{~nm}$ ). Further details on the MERIS and its measurement modes are given by Bezy et al. (2000).

The correlation plot of the ART-retrieved AOT and ground-based AERONET measurements of $\tau$ (Holben et al., 1998) is shown in Fig. 3 at the AERONET wavelengths $440 \mathrm{~nm}$ and $670 \mathrm{~nm}$. Generally, the agreement is good.

The summary of results for 9 AERONET stations is shown in Tables 1 and 2. Figure 4 gives the difference $\Delta=$ AOT (satellite)-AOT (AERONET) for both wavelengths as the function of AERONET-measured AOT. One can see that

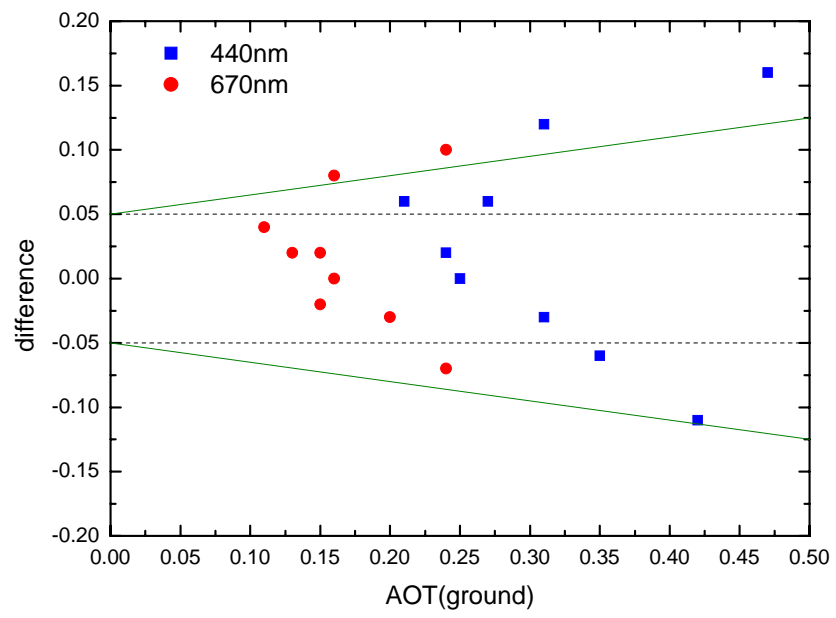

Fig. 4. The difference in AOTs derived from satellite and ground. The boundary errors (upper and lower lines) for the MODIS retrievals over land are also shown.

ART performs quite well for all AERONET sites. Absolute differences in the retrieved and AERONET-measured $\tau$ are smaller than 0.06 for most of cases at both wavelengths, which is a promising result. Some differences can be explained by the fact that the satellite-derived AOT is for $5 \times 5 \mathrm{~km}$ grid box over the AERONET site. Therefore, it can be influenced by the local distribution of pollution not seen by AERONET point measurements and vice versa. We used $5 \times 5 \mathrm{~km}$ grid box to decrease the effects of random errors of measurements and of small-scale variations of the surface albedo. As it follows from Table 2, the average values of ground and satellite-derived AOTs are very close. We conclude that the aerosol optical thickness is determined quite accurately for both channels and is within MODIS AOT estimation error $\pm 0.05 \pm 0.15 \tau$ (Levy, 2009) for most of cases (see Fig. 4).

The retrieved Angstrom parameter $\alpha$ is given in Table 3 . These results show that ART also makes accurate estimates of $\alpha$. The average value of $\alpha$ for all AERONET stations is 1.45 and it is 1.41 for satellite observations. It follows that the absolute values of differences between values of $\alpha$ derived from satellite and ground observations $\Delta=\alpha^{s}-\alpha^{a}$ do not exceed 0.3.

The spatial distributions of aerosol optical thickness at $412 \mathrm{~nm}$ and the Angstrom exponent for almost cloud free scene over Germany and neighboring countries are given in Figs. 5, 6, respectively. We see that the Angstrom coefficient does not vary considerably over the scene being around 1.3, which is close to average value for the atmospheric conditions in Germany. Although we see a considerable variability in the retrieved AOT with larger values in the Northern Germany. 
Table 1. The AERONET $\tau^{a}$ and satellite $\tau^{s}$ retrieved values of the aerosol optical thickness for 13 September 2005 (10:00 UTC) for different stations at $\lambda=440,670 \mathrm{~nm}$. The geographical coordinates of the stations are given as well. The differences $\Delta$ of AOTs for satellite $(s)$ and AERONET (a) observations are also given (at wavelengths 440 and $670 \mathrm{~nm}$ ).

\begin{tabular}{|c|c|c|c|c|c|c|c|c|}
\hline Station & Position & Time & $\tau_{440}^{a}$ & $\tau_{440}^{S}$ & $\Delta_{440}$ & $\tau_{670}^{a}$ & $\tau_{670}^{S}$ & $\Delta_{670}$ \\
\hline Hamburg & $\begin{array}{l}53.568 \mathrm{~N} \\
9.973 \mathrm{E}\end{array}$ & 09:52 & 0.21 & 0.27 & 0.06 & 0.11 & 0.15 & 0.04 \\
\hline Helgoland & $\begin{array}{l}54.178 \mathrm{~N} \\
7.887 \mathrm{E}\end{array}$ & 09:45 & 0.27 & 0.33 & 0.06 & 0.15 & 0.17 & 0.02 \\
\hline Cabauw & $\begin{array}{l}51.971 \mathrm{~N} \\
4.927 \mathrm{E}\end{array}$ & 09:57 & 0.25 & 0.25 & 0.00 & 0.15 & 0.13 & -0.02 \\
\hline Den Haag & $\begin{array}{l}52.110 \mathrm{~N} \\
4.327 \mathrm{E}\end{array}$ & 09:44 & 0.31 & 0.43 & 0.12 & 0.16 & 0.24 & 0.08 \\
\hline Leipzig & $\begin{array}{l}51.354 \mathrm{~N} \\
12.435 \mathrm{E}\end{array}$ & 10:06 & 0.24 & 0.26 & 0.02 & 0.13 & 0.15 & 0.02 \\
\hline Mainz & $\begin{array}{l}49.999 \mathrm{~N} \\
8.300 \mathrm{E}\end{array}$ & 09:58 & 0.42 & 0.31 & -0.11 & 0.24 & 0.17 & -0.07 \\
\hline Karlsruhe & $\begin{array}{l}49.093 \mathrm{~N} \\
8.428 \mathrm{E}\end{array}$ & 09:43 & 0.31 & 0.28 & -0.03 & 0.16 & 0.16 & 0.00 \\
\hline Venice & $\begin{array}{l}45.314 \mathrm{~N} \\
12.508 \mathrm{E}\end{array}$ & 09:29 & 0.47 & 0.63 & 0.16 & 0.24 & 0.34 & 0.10 \\
\hline Bremen* & $\begin{array}{l}53.05 \mathrm{~N} \\
8.78 \mathrm{E}\end{array}$ & $10: 06$ & 0.35 & 0.29 & -0.06 & 0.2 & 0.17 & -0.03 \\
\hline
\end{tabular}

* not in AERONET

Table 2. The difference $\Delta$ between satellite and AERONET measurements of AOT (averaged for all stations shown in Table 1) at the wavelengths 440 and $670 \mathrm{~nm}$. The average values of AOTs are also given at both wavelengths both for AERONET $(a)$ and satellite $(s)$ observations.

\begin{tabular}{cccc}
\hline$\lambda, \mathrm{nm}$ & $\bar{\tau}^{a}$ & $\bar{\tau}^{s}$ & $\Delta \tau$ \\
\hline 440 & 0.31 & 0.34 & 0.03 \\
670 & 0.17 & 0.19 & 0.02 \\
\hline
\end{tabular}

\subsection{Particulate matter vertical columns}

The derived values of AOT and $\alpha$ were used to determine the particulate matter vertical columns. This was done according to the procedure described in the previous section. First of all, the effective radius and the values of $V$ and $C_{\text {ext }}$ were assessed. Then PMVC is calculated using Eq. (4). The corresponding maps are presented in Figs. 7, 8 for $a_{e f}$ and $m$, respectively. The value of $\alpha$ (and $a_{e f}$ ) does not vary much along the scene. Therefore, the PMVC pattern shown in Fig. 8 is similar to that of AOT (but not identical).

The following features can be derived from this map:

- the increased level of pollution in the Frankfurt and Berlin areas;

- clear air north of Alps and in the South-Western Germany (Freiburg);
Table 3. Angstrom exponents $\alpha_{g}$ (ground-derived) and $\alpha_{s}$ (satellite-derived) for different stations. Also corresponding relative differences $\delta=\left(\alpha_{S}-\alpha_{g}\right) / \alpha_{g}$ are given (in percent).

\begin{tabular}{lllr}
\hline Station & $\alpha_{g}$ & $\alpha_{s}$ & $\delta, \%$ \\
\hline Hamburg & 1.54 & 1.44 & -6.49 \\
Helgoland & 1.4 & 1.54 & 10.00 \\
Cabauw & 1.21 & 1.43 & 18.18 \\
Den Haag & 1.57 & 1.41 & -10.19 \\
Leipzig & 1.46 & 1.36 & -6.85 \\
Mainz & 1.33 & 1.41 & 6.02 \\
Karlsruhe & 1.57 & 1.36 & -13.38 \\
Venice & 1.6 & 1.46 & -8.75 \\
Bremen & 1.33 & 1.32 & -0.75 \\
\hline
\end{tabular}

- clear air in the Northwestern Germany and eastern part of Belgium;

- pollution around Amsterdam.

Overall, it appears that the analysis of PMVC maps could be of benefit for national and also international environmental agencies, especially as far as the studies of the transboundary pollution transfer is of concern (see, e.g., the area east of Berlin). 

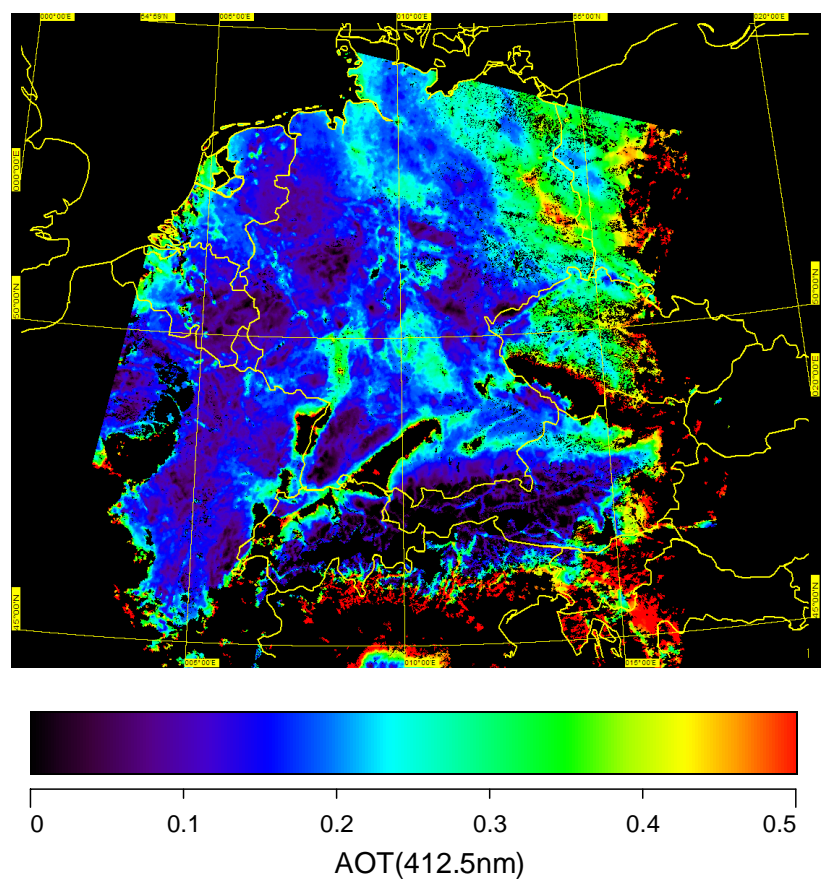

Fig. 5. The AOT spatial distribution at the wavelength $412.5 \mathrm{~nm}$. The pixels with large error due to incorrect cloud detection and 3-D effects are clearly visible at edges and near the Alps (the red colour). This problem appears also in other derived maps given below.

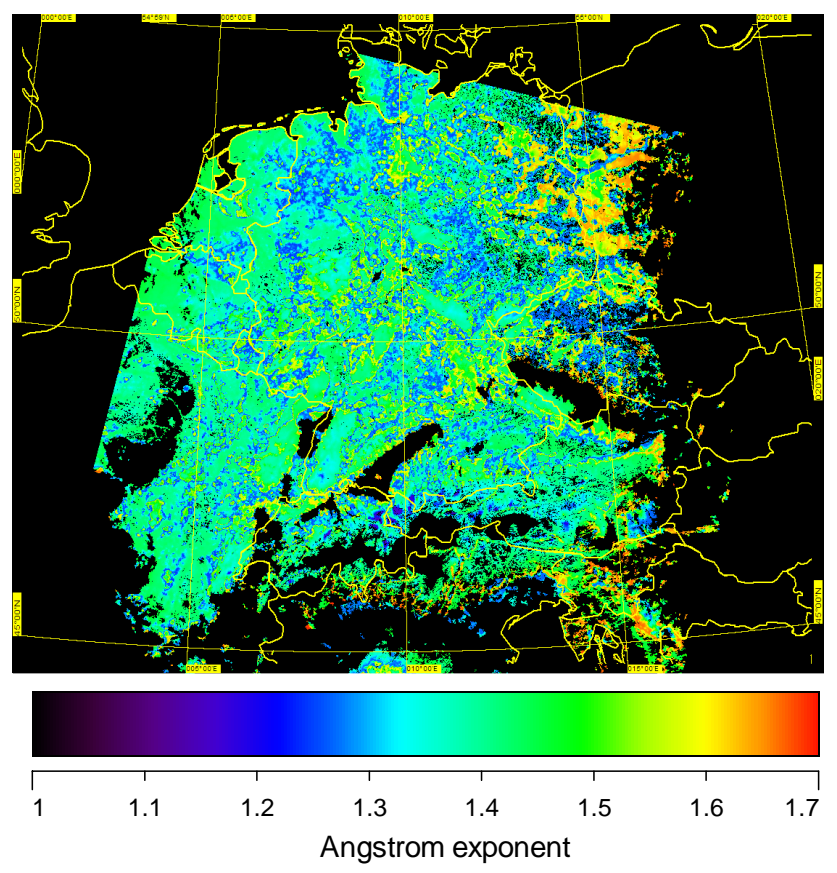

Fig. 6. The derived Angstrom exponent spatial distribution.
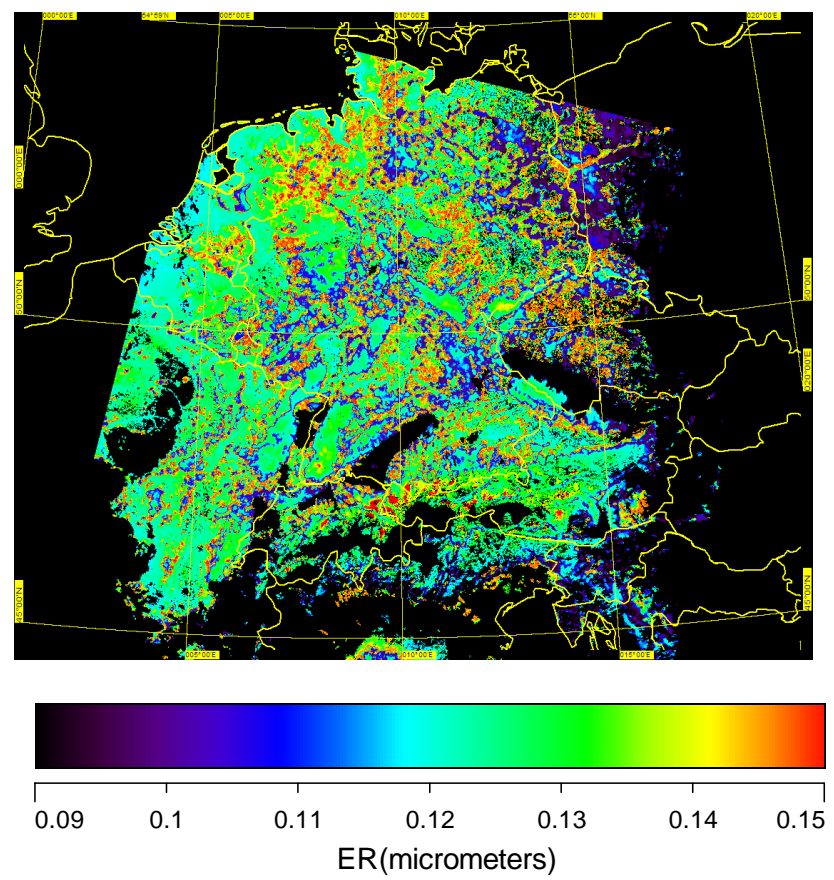

Fig. 7. The derived effective radius spatial distribution.
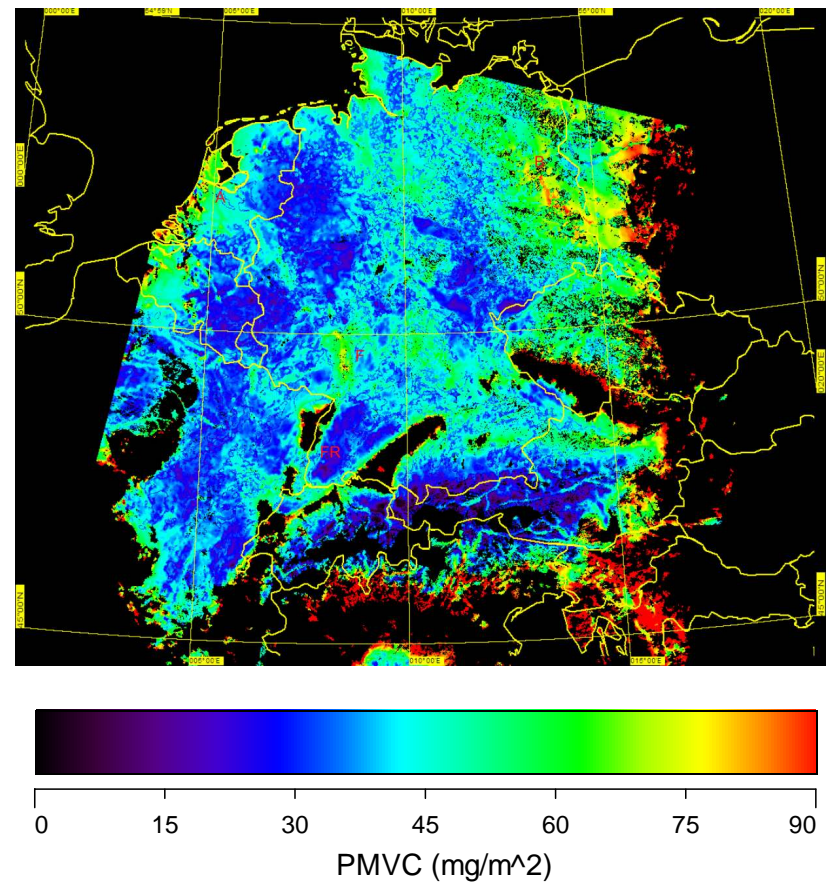

Fig. 8. The particulate matter vertical column map (A-Amsterdam, B-Berlin, F-Frankfurt, FR-Freiburg). 


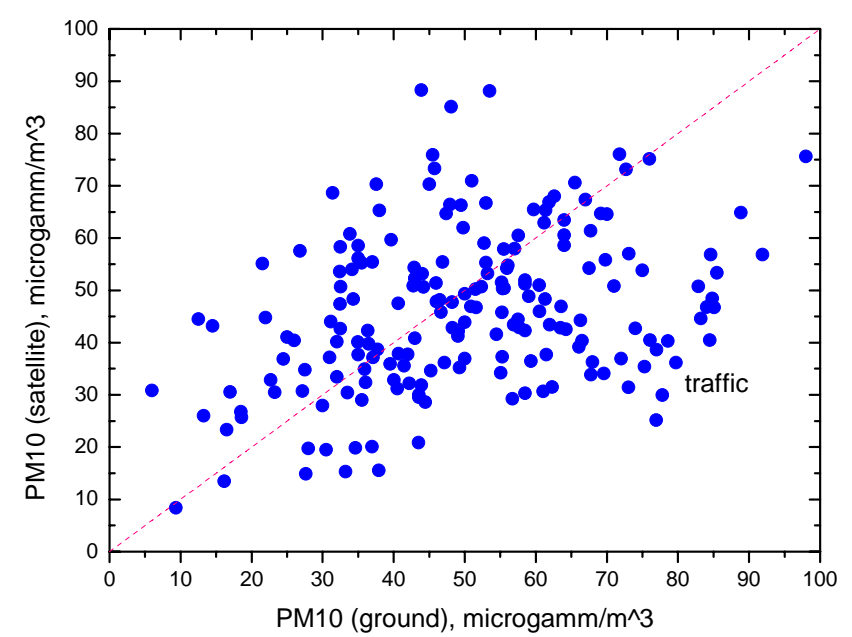

Fig. 9. The correlation plot for $\mathrm{PM}_{10}$ derived from ground and satellite measurements. The ECMWF boundary layer height information was used in the determination of $\mathrm{PM}_{10}(M=m / L)$. Traffic sites correspond to values of $\mathrm{PM}_{10} \geq 70 \mu \mathrm{g} / \mathrm{m}^{3}$ on the figure.

It is difficult to validate the derived PMVC. This is because of several circumstances:

1. The results of ground measurements can vary spatially inside of one MERIS pixel (e.g., close to the road and $1 \mathrm{~km}$ from the road). Therefore, for the correct comparisons, ground measurements must be performed not at one place but in several places in the pixel.

2. AOTs measured from ground and space represent the same physical quantity, namely, the aerosol extinction coefficient integrated along the vertical path. This is not the case for the satellite and ground-derived PM. Indeed, the satellite-derived PMVC represents the whole atmospheric column from the ground to the TOA. Ground measurements are performed at the height $h=2 \mathrm{~m}$ above the ground level. Also the weighting methods are used to determine the aerosol mass. Therefore, mostly dry fraction of aerosol is measured and not the ambient aerosol as it is done for the satellite measurements. Although indeed attempts can be made to correlate ground measured PM with $M=m / L$, where the aerosol layer thickness $L$ must be assessed using, e.g., lidar measurements (Kokhanovsky et al., 2006). The boundary layer height as derived from ECMWF analysis has some uncertainty, which contributes to the discrepancy of satellite and ground measurements.

3. The aerosol layer can be decoupled from the surface. Then the satellite signal is influenced mostly by the aerosol in this layer and, therefore, the contribution of light interacted with the aerosol at the ground level to the satellite measurements is negligible and can not be assessed.

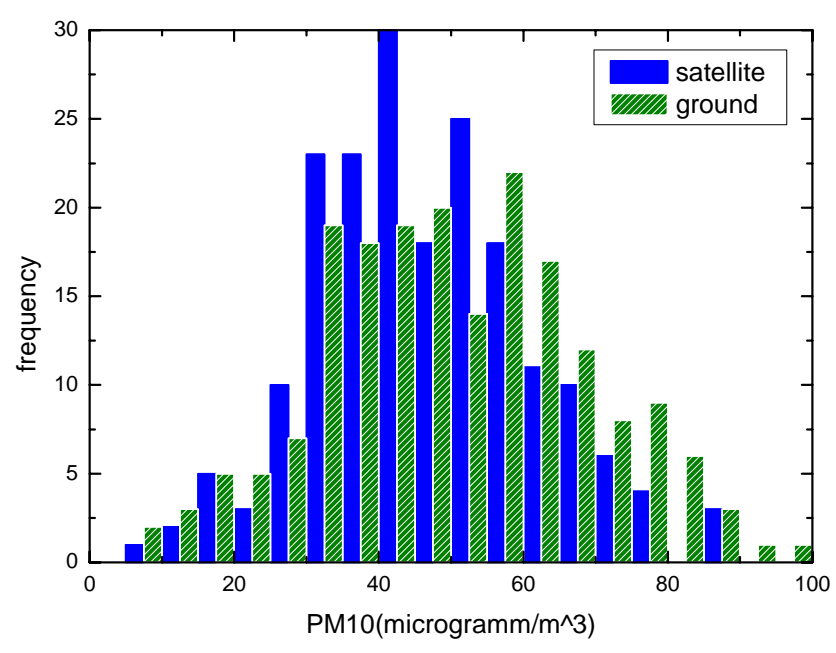

Fig. 10. The same as in Fig. 9 except in the form of a histogram. It follows that satellite measurements somewhat underestimate $\mathrm{PM}_{10}$ values.

These factors lead to the fact that the satellite-derived and ground-measured PM poorly correlate. Poor correlation is also seen in our Fig. 9, where we correlate $\mathrm{PM}_{10}$ (PM with diameters of particles smaller than $10 \mu \mathrm{m}$ ) with MERIS PM $M=m / L$ measurements, where $L$ is the boundary layer height taken from the ECMWF analysis.

The part of poor correlation can be explained by the fact that the spatial distribution of used satellite imagery is not capable to detect small scale perturbations of PM detectable using ground measurements. However, this does not mean that satellite measurements are useless with respect to particulate matter pollution monitoring. They just bring additional type of information as shown in Fig. 8. Also we found that average values are close for ground and satellite measurements. For the cases shown in Fig. 9, the average ground $\mathrm{PM}_{10}$ is $50 \mu \mathrm{g} / \mathrm{m}^{3}$ and it is just by $4 \mu \mathrm{g} / \mathrm{m}^{3}$ smaller for the satellite retrievals (see Fig. 10 as well). More importantly, ground measurements of PM in different countries differ so if you put two instruments at the same place, they often do not produce the same results for $\mathrm{PM}_{10}$ due to differences in instruments and software. Satellite measurements have a shortcoming that they are related not to point measurements but to vertical columns. So information is not resolved with respect to vertical and horizontal coordinates. It is also not resolved with respect to time because (if the measurements are performed not from a geostationary orbit) the measurements only once per day are possible (e.g., morning around 10:00 local time for ENVISAT). Even a small subpixel cloud or snow fraction of $10 \%$ or so destroys all retrievals completely. This reduces the capabilities of satellite methods to observe PMVC even further.

The superiority of satellite data is in their low cost, global processing (for any place on the planet) and the possibility to assess the pollution levels over a large area. In particular, ground measurements are not capable to cover the whole 
country with $1 \mathrm{~km}$-scale network but this is easy done with satellite measurements (even finer resolution $(0.3 \times 0.3 \mathrm{~km})$ is possible with MERIS observations). Also satellite data can be used for processing long term data of the same quality and using the same algorithm. This helps to identify trends relevant for environmental and climatic studies. Clearly, the trend analysis requires thorough calibration control and (for long-term monitoring) inter-satellite cross calibration, which is very demanding.

\section{Conclusions}

We have proposed a technique to determine the particulate matter vertical columns from space-based observations. The technique was compared with ground measurements of $\mathrm{PM}_{10}$ in Germany. Results obtained are encouraging. The spaceborne observations can not substitute ground-based measurements due to problems with the technique for cloudy and bright underlying surface (e.g., snow) scenes, etc. However, they can be used to enhance the accuracy of interpolation between single point retrievals as performed by the ground network nowadays. They can be used also for the improvement of aerosol global modeling. The derived values of $a_{e f}$ are of importance for the estimations of surfaces available for atmospheric heterogeneous reactions. The maps as shown in Fig. 9 can be utilized by environmental agencies in their daily work in future. An interesting point not considered in this work is the determination of $\mathrm{PM}_{2.5}$ from space. Namely these small particles with sizes below $2.5 \mu \mathrm{m}$ are of major importance as far as health issues are of concern. One way to determine $\mathrm{PM}_{2.5}$ concentration is to use correlations between $\mathrm{PM}_{2.5}$ and derived $\mathrm{PM}_{10}$ valid for a particular location. Such correlations appear to be quite robust.

Acknowledgements. This work was supported by the DFG Project BU688/18-1. Further we like to acknowledge the contribution of ground-based $\mathrm{PM}_{10}$ data of the different German federal countries networks by the Umweltbundesamt, especially W. Bräuniger, W. Garber and M. Wichmann-Fiebig. Authors are thankful to P. Glantz for providing the results of ECMWF analysis of planetary boundary layer height to us. Discussions with J. P. Burrows, W. von Hoyningen-Huene, and also A. P. Ivanov are very much appreciated.

W. von Hoyninge-Huene provided the ground truth data for the site Bremen. This is acknowledged with many thanks.

Edited by: R. Martin

\section{References}

Al-Saadi, J., Szykman, J., Pierce, R. B., et al.: Improvings national air quality forecasts with satellite aerosol observations, B. Am. Meteorol. Soc., 9, 1249-1261, 2005.
Altshuller, A. P.: Atmospheric sulfur dioxide and sulfate: distribution of concentrations at urban and non-urban sites in the United States, Environ. Sci. Technol., 7, 709-712, 1973.

Bezy, J.-L., Delwart, S., and Rast, M.: MERIS - a new generation of ocean colour sensor onboard ENVISAT, ESA Bull.-Eur. Space, 103, 48-56, 2000.

Borell, P., Borell, P. M., Burrows, J. P., and Platt, U. (Eds.): Sounding the troposphere from space: a new era of atmospheric chemistry, Berlin, Springer-Verlag, 2004.

Burrows, J. P.: Current and future passive remote sensing techniques used to determine atmospheric constituents, in: Approaches to Scaling of Trace Gas Fluxes in Ecosystems, edited by: Bouwman, A. F., Dordrecht, Elsevier, 317-347, 1999.

Desboeufs, K. V. and Cautenet, G.: Transport and mixing zone of desert dust and sulphate over Tropical Africa and the Atlantic Ocean region, Atmos. Chem. Phys. Discuss., 5, 5615-5644, 2005, http://www.atmos-chem-phys-discuss.net/5/5615/2005/.

Fraser, R. S.: Satellite measurement of mass of Sahara dust in the atmosphere, Appl. Optics, 15, 2471-2479, 1976.

Fraser, R. S., Kaufman, Y. J., and Mahoney, R. L.: Satellite measurements of aerosol mass and transport, Atmos. Environ., 18, 2577-2584, 1984.

Gasso, S. and Hegg, D. A.: Comparison of columnar aerosol optical properties measured by the MODIS airborne simulator with in situ measurements: A case study, Remote Sens. Environ., 66, 138-152, 1997.

Gasso, S. and Hegg, D. A.: On the retrieval of columnar aerosol mass and CCN concentration by MODIS, J. Geophys. Res., 108(D1), 4010, doi:10.1029/2002JD002382, 2003.

Griggs, M.: Measurements of atmospheric aerosols over water using ERTS-1 data, Air Pollution Control Association Journal, 25, 622-626, 1975.

Griggs, M.: Satellite observations of atmospheric aerosols during the EOMET cruise, Journal of Atmospheric Sciences, 36, 695698, 1979.

Hanel, G.: The properties of atmospheric aerosol particles as a function of relative humidity at thermodynamic equilibrium with surrounding moist air, Adv. Geophys., 19, 73-188, 1976.

Holben, B. N., Eck, T. F., Slutsker, I., et al.: AERONET - a federated instrument network and data archive for aerosol characterization, Remote Sens. Environ., 66, 1-16, 1998.

Katsev, I. L., Prikhach, A. S., Zege, E. P., Ivanov, A. P., and Kokhanovsky, A. A.: Iterative procedure for retrieval of spectral aerosol optical thickness and surface reflecatnce from satellite data using fast radiative transfer code and its application to MERIS measurements, in: Satellite Aerosol Remote Sensing over Land, edited by: Kokhanovsky, A. A. and de Leeuw, G., Berlin, Springer-Praxis, 101-134, 2009.

Kaufman, Y. J. and Fraser, R. S.: Satellite measurements of largescale air pollution: Methods, J. Geophys. Res., 95(D7), 98959909, 1990.

Kokhanovsky, A. A., von Hoyningen-Huene, W., and Burrows, J. P.: Atmospheric aerosol load as derived from space, Atmos. Res., 81, 176-185, 2006.

Kokhanovsky, A. A.: Aerosol Optics, Berlin, Praxis-Springer, 2008.

Kokhanovsky, A. A. and de Leeuw, G. (Eds.): Satellite Aerosol Remote Sensing over Land, Berlin, Springer-Praxis, 2009.

Levy, R. C.: The dark-land MODIS collection 5 aerosol retrieval: 
algorithm development and product evaluation, in: Satellite Aerosol Remote Sensing over Land, edited by: Kokhanovsky, A. A. and de Leeuw, G., Berlin, Springer-Praxis, 19-68, 2009.

Liou, K. N.: Introduction to Atmospheric Radiation, N. Y., Academic Press, 2002.

Mishchenko, M. I., Cairns, B., Chowdhary, J., et al.: Remote sensing of terrestrial tropospheric aerosols from aircraft and satellites, J. Phys. Conf. Ser., 6, 73-89, 2005.

Pope, C. A., Burnett, R. T., Thun, M. J., et al.: Lung cancer, cardiopulmonary mortality and long-term exposure to fine particulate air pollution, J. Amer. Med. Assoc., 287, 1132-1141, 2002.

Remer, L. A., Kaufman, Y. J., Tanré, D., et al.: The MODIS Aerosol Algorithm, Products and Validation, J. Atmos. Sci., 62, 947-973, 2005.

Tomasi, C., Vitale, V., Petkov, B., et al.: Improved algorithm for calculations of Rayleigh-scattering optical depth in standard atmospheres, Appl. Optics, 44, 3320-3341, 2005.

van de Hulst, H. C.: Light Scattering by Small Particles, N. Y., Dover, 1981. von Hoyningen-Huene, W., Freitag, M., and Burrows, J. P.: Retrieval of aerosol optical thickness over land surfaces from top-of-atmosphere radiance, J. Geophys. Res., 108(D9), 4260, doi:10.1029/2001JD002018, 2003.

von Hoyningen-Huene, W., Kokhanovsky, A. A., Burrows, J. P., et al.: Simultaneous determination of aerosol and surface characteristics from top-of-atmosphere reflectance using MERIS on board of ENVISAT, Adv. Space Res., 37, 2172-2177, 2006.

WMO International Association for Meteorology and Atmospheric Physics Radiation Commission: A preliminary cloudless standard atmosphere for radiation computation, World Climate Program, WCP-112, WMO TD-24, World Meteorological Organisation, Geneva, 1986.

Xia, X. A., Chen, H. B., Wang, P. C., et al.: Variation of columnintegrated aerosol properties in a Chinese urban region, J. Geophys. Res., 111, D05204, doi:10.1029/2005JD006203, 2006. 